\section{A STRUCTURAL STUDY ON THE POLYMORPHISM OF} DOCOSANE-1,22-DIOL

$\underline{\text { K. Uno }}^{1}$ N. Nakamura ${ }^{1}$ Y. Ogawa

${ }^{1}$ Ritsumeikan University of Science and Engineering Department of Applied Chemistry 1-1-1 Nojihigashi KUSATSU SIGA 525-8577 JAPAN

${ }^{2}$ Department of Chemistry, Faculty of Science, Kumamoto University, 2-39-1 Kurokami, Kumamoto 860-8555, Japan.

The two different crystal structures of docosane-1,22-diol, of which the polymorphism was dependent upon the crystallizing condition, were analyzed by single crystal X-ray diffraction method. All measurements were made on a Rigaku AFC-5R diffractometer with graphite monochromatized $\mathrm{Cu} \mathrm{Ka}$ radiation. All calculations were performed using TEXSAN. The non-H atoms were refined anisotropically. The $\mathrm{H}$ atoms were located from a difference Fourier map, and were allowed to refine isotropically for the final refinements. The isotropic displacement parameters were fixed at $1.2 \mathrm{Ueq}$ of the parent atom. One of the crystal structures was a monoclinic system $(a=9.691(4) \AA, b$ $\left.=5.235(3) \AA, c=43.617(4) \AA, \beta=97.57(2)^{\circ}, Z=4\right)$ with a space group $C 2 / c$. The $\mathrm{R}\left(\mathrm{F}^{2}>2 \sigma\left(\mathrm{F}^{2}\right)\right)$ value was converged to 0.041 by the final refinement. In the molecular structure, the hydrocarbon skeleton included both terminal hydroxy groups had an all-trans conformation. The long axis of the molecule was inclined to the ab plane, and the molecules formed layers in a herring-bone arrangement, just as in the tilt-smectic phase of liquid crystals. Another crystal structure was a monoclinic system $(\mathrm{a}=5.045(2) \AA, \mathrm{b}=7.256(4) \AA, \mathrm{c}=$ $\left.30.290(2) \AA, \beta=93.23(2)^{\circ}, Z=2\right)$ with a space group $P 2_{1}$. The $\mathrm{R}\left(\mathrm{F}^{2}>2 \sigma\left(\mathrm{F}^{2}\right)\right)$ value was converged to 0.038 by the final refinement. In the molecular structure, one of the hydroxy groups adopted a gauche conformation with respect to the hydrocarbon skeleton, whereas the other adopted a trans conformation. The long axis of the molecule was normal to the ab plane, and the molecules formed layers which were similar to those of the smectic A liquid crystal.

\section{Keywords: POLYMORPHISM CRYSTAL STRUCTURE LIQUID} CRYSTAL

\section{Acta Cryst. (2002). A58 (Supplement), C338}

STRUCTURES OF LiCaAIF 6 AND LiSrAlF 6 AT 120 AND 300 K BY SYNCHROTRON X-RAY SINGLE CRYSTAL DIFFRACTION

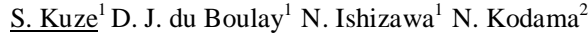

${ }^{1}$ Tokyo Institute of Technology Materials and Structures Laboratory 4259 Nagatsuta, Midori YOKOHAMA 226-8503 JAPAN ${ }^{2}$ Akita University

The solid solution series with end members lithium calcium hexafluoroaluminate (LiCAF), $\mathrm{LiCaAlF}_{6}$, and lithium strontium hexafluoroaluminate ( $\mathrm{LiSAF}$ ), $\mathrm{LiSrAlF}_{6}$, are known as potential candidates for tunable laser host materials. Though the structure of the solid solution is essentially of colquiriite-type with trigonal $P-31 c$ space group, several optical properties of the end members change in a slightly different manner with temperature, which motivated us to carry out structural studies at different temperatures. Structures of LiCAF and LiSAF were investigated at 120 and $300 \mathrm{~K}$ by the synchrotron X-ray single crystal diffraction using the horizontaltype four-circle diffractometer at beamline 14A, Photon Factory, KEK. The wavelength $0.8048 \AA$ was chosen to reduce $\mathrm{Sr}$ fluorescence. With the exception of $\mathrm{c}$ for LiSAF, all cell parameters reduced with temperature from 300 to $120 \mathrm{~K}$. All the $\mathrm{AlF}_{6}, \mathrm{CaF}_{6}$ and $\mathrm{SrF}_{6}$ octahedra became more distorted at $120 \mathrm{~K}$. It was noted that $\mathrm{CaF}_{6}$ octahedra of LiCAF shrank in the c-direction at $120 \mathrm{~K}$, while the $\mathrm{SrF}_{6}$ octahedra of LiSAF became elongated along c at $120 \mathrm{~K}$. The different temperature dependency of the cell parameters is reflected in the different distortion modes between $\mathrm{CaF}_{6}$ and $\mathrm{SrF}_{6}$ octahedra from a microscopic structural point of view.

Keywords: COLQUIRIITE LASER HOST MATERIAL LOW TEMPERATURE STRUCTURE
Acta Cryst. (2002). A58 (Supplement), C338

CRYSTAL STRUCTURE OF Ge-DOPED RUBIDIUM TITANYL PHOSPHATE

J. Gustafsson G. Svensson J. Albertsson

Chalmers University of Technology Inorganic Chemistry Dept. Kemivaegen 10 GOTHENBURG S-412 96 SWEDEN

Rubidium titanyl phosphates, $\mathrm{RbTiOPO}_{4}$ (RTP) and other compounds in this structural family are well known for their non-linear optical properties. Some other characteristics like high optical damage thresholds and wide transparency windows are also beneficial for choosing these materials in optical applications. The properties may be varied by inclusion and/or replacement of rubidium, titanium and phosphorous by other elements. In this study titanium is partly replaced by germanium. The crystals were grown by self-nucleation in a so-called self-flux, i.e. no other elements than those present in the crystals are included in the flux. All crystals were transparent and colorless whereas slightly different morphologies were found. The composition of the $\mathrm{RbGe}_{0.05} \mathrm{Ti}_{0.95} \mathrm{OPO}_{4}$ has been verified by SEM-EDX analysis and the structure determined from X-ray diffraction single-crystal data at 293 K. As expected, the compound is isostructural with potassium titanyl phosphate (KTP) i.e. orthorhombic with space group Pna21. Germanium is located close to one of the two titanium sites while the other titanium site is germanium-free. Inclusion of germanium decreases the cell volume slightly compared to RTP as it does for the germanium doped KTP. The $\mathrm{GeO}_{6}$ octahedra are also less distorted than the corresponding $\mathrm{TiO}_{6}$ octahedra, which is in accordance with the previous studies of crystals of $\mathrm{KGe}_{\mathrm{x}} \mathrm{Ti}_{1-\mathrm{x}} \mathrm{OPO}_{4}$.

\section{Keywords: NON LINAER TITANYL PHOSPHATE STRUCTURE}

\section{Acta Cryst. (2002). A58 (Supplement), C338 STRUCTURE REFINEMENT OF A NEAR-STOICHIOMETRIC LITHIUM TANTALATE}

M. Okui N. Iyi K. Kitamura S. Takekawa S. Fukushima

National Instiute for Materials Science Harima Office, Advanced Materials Science SPring-8, Kouto1-1-1 MIKADUKI-CHO, SAYO-GUN HYOGOKEN 679-5198 JAPAN

Recent years, near-stoichiometric lithium tantalate has been attracting attentions as promising material for frequency conversion and other optical devices. In this study, the crystal structure of lithium tantalate was determined based on X-ray single crystal diffraction data using near-stoichiometric crystal grown by double crucible Czochralski method. The diffraction data were measured by Mo Ka radiation using a four-circle diffractometer, and 794 reflections were collected in the theta range from 5 to $35^{\circ}$ in reciprocal lattice space. The result of the experiment is consistent with space group $R 3 c$. The scale factor, occupancies of cations, atomic positions, and temperature factors were refined by least squares method using 107 independent reflections, of which the each intensity obtained by averaging those of equivalent reflections, were used. The total amount of lithium and tantalum ion was fixed stoichiometric at the occupancy refinement. The residual $\mathrm{R}$ and $\mathrm{wR}$ converged on 0.023 and 0.025 , respectively. The result of the refinement strongly suggests the possibility of partial replacement of lithium site by tantalum. It also suggests that lithium site is fairly closer to tantalum site compared to that in previous reports.
Keywords: NEAR-STOICHIOMETRIC LITHIUM TANTALATE STRUCTURE REFINEMENT X-RAY SINGLE CRYSTAL DIFFRACTION 